\title{
Carpal Tunnel Syndrome in Occupational Medicine Practice
}

\author{
Joanna Bugajska \\ Anna Jędryka-Góral \\ Iwona Sudoł-Szopińska \\ Department of Ergonomics, Central Institute for Labour Protection \\ - National Research Institute, Poland \\ Kazimierz Tomczykiewicz \\ Department of Neurology, Military Institute of the Health Services, Poland
}

Work-related overload syndromes are chiefly associated with the upper limbs, where carpal tunnel syndrome (CTS) plays a leading role. This article analyses methods of diagnosing CTS, with special emphasis on those that can be used by physicians in early diagnosis of CTS in workers doing monotonous work. It also discusses occupational (e.g., assembly work, typing, playing instruments, packaging and work associated with the use of a hammer or pruning scissors) and extra-occupational factors (e.g., post-traumatic deformation of bone elements of the carpal tunnel, degenerative and inflammatory changes in tendon sheaths, connective tissue hypertrophy or formation of crystal deposits) leading to CTS; diagnostic methods (subjective symptoms, physical examination, manual provocative tests, vibration perception threshold, electrophysiological examination and imaging methods); and therapeutic and preventive management tools accessible in occupational medicine practice.

carpal tunnel syndrome diagnostic methods occupational medicine

\section{INTRODUCTION}

Musculoskeletal disorders (MSDs) are the most frequent causes of chronic pain, absence from work and disability leading to temporary or permanent incapacity to work. In recent years diseases of the musculoskeletal system and connective tissue constituted the basis of the second greatest number of certificates confirming total inability to work issued in Poland. In total, in 2000, 14934 certificates $(15.4 \%$ of all certificates) and in 2001, 11064 certificates (13.3\%) resulted from those diseases [1]. It is estimated that in the USA, $13.9-15 \%$ of the population have MSDs [2, 3].

The extent and significance of the problem of MSDs may be confirmed by the fact that the World Health Organization (WHO) declared 2000-2010 a Bone and Joint Decade. Those work-related MSDs, which are defined as overload syndromes, pose a special problem to occupational medicine professionals. Additionally, chronic degeneration and inflammatory diseases of the loco-motor system require not only significant expenditure on treatment, rehabilitation and welfare, but most

This paper has been prepared as part of task 3.A.01 of the National Programme "Adaptation of Working Conditions in Poland to European Union Standards", partly supported-within the scope of research and development-in 2002-2004 by the State Committee for Scientific Research of Poland. The Central Institute for Labour Protection - National Research Institute was the Programme's main co-ordinator.

Correspondence and requests for offprints should be sent to Joanna Bugajska, Department of Ergonomics, Central Institute for Labour Protection - National Research Institute, Czerniakowska 16, 00-701 Warszawa, Poland. E-mail: <jobug@ciop.pl>. 
of all they lead to the deterioration of the quality of life and to incapacity to work [4]. This is particularly important in view of the ageing of the populations in many developed countries, including Poland, caused primarily by the extension of human life. Work-related overload syndromes are predominantly associated with upper limbs. Nine point four percent of the MSDs of the upper limbs are located in the area of hands and wrists. The carpal tunnel syndrome (CTS) accounts for $1.5 \%$ of those; $0.4 \%$ are caused by tendenitis [5].

Symptoms of these syndromes, of CTS in particular, belong to the leading factors in decreasing mobility and independence in everyday life. They affect the quality of life in the "third age", defined as the period of 10-30 years after retiring [6, 7, 8]. According to Ilmarinen [7], on the one hand, work environment factors impair the quality of life measured with limitations in everyday activities and, on the other, the quality of life in the third age may be raised by improving working conditions during the period of professional activity. These conclusions, based on a longitudinal, multi-year study carried out on the Finnish workforce, pose a challenge to all who deal with safety and health at work.

The authors of the present paper assume that a broader dimension of the problem is inevitable and they would like to stress the importance of illness prevention in the ever-growing number of elderly people and of activities aimed at reducing risk factors at work and early diagnosis of the syndrome of upper limb overload.

Therefore the aim of this article is to analyse the methods of diagnosing CTS with special emphasis on those that can be used by physicians in early diagnosis of CTS in workers doing monotonous work.

\section{FACTORS CAUSING CTS}

CTS is a neuropathy caused by a compression of the median nerve in its passage through the carpal tunnel [9. 10]. The basic clinical symptoms include pain, numbness and paraesthesia in the median nerve. In addition, there are symptoms of damage also to the motor part of this nerve.
The causes of CTS may be general or local. In general disorders, the cause of this neuropathy is the tightness in the carpal tunnel which occurs during increased tissue pressure due to, e.g., connective tissue hypertrophy or formation of crystal deposits. The causes include hormonal disorders (acromegalia and hypotyreosis), pregnancy and menopause, metabolic diseases (diabetes, amyloidosis, obesity, pseudogout and mucopolysaccharidosis), diseases of blood vessels (arterial hypertension, Raynaud's disease and median artery thrombosis) and others (allergic reaction) [11, 12].

The local causes of CTS include posttraumatic deformation of bone elements of the carpal tunnel, deep postburn scars, degenerative and inflammatory changes in tendon sheaths, malformations in muscles, bones and vessels in the wrist joint, tumours and paratumours, and mycotic lesions.

CTS is one of the most frequent work-related locomotor system disorders and is more frequent in persons whose work or hobby requires repetitive actions, application of significant force and uncomfortable position of the wrist and hand. CTS incidence tends to increase with age and the number of working years; the syndrome is more often found in women than in men [13, 14]. The significance of the musculoskeletal system overload in the etiology of the syndrome is exemplified by its increased incidence in persons with paraplegia, who live in a wheelchair, as compared to the population without this disability [15].

Typical occupational activities causing the said problems include grinding, polishing, sandblasting, assembly work, typing, counting money, playing instruments, using surgical instruments, packaging, cooking, butchering, washing by hand, scrubbing, typing, computer work, work associated with the use of a hammer or pruning scissors and the like [13, 16, 17, 18, 19, 20, 21]. Factors associated with work (high repetitiveness of movements, the force used and an awkward position of the hand) may lead to muscular fatigue and discomfort in the carpal area; these conditions will abate quickly if the interval between such activities is sufficiently long. However, when 
work is continued despite fatigue, there may be symptoms of tendonitis and swelling in the carpal tunnel, resulting in an increased compression of the tunnel [22]. The pressure increase in the carpal tunnel is accompanied by perfusion disturbances and also a mechanical compression of the median nerve, which causes symptoms of irreversible damage [5, 23, 24].

\section{DIAGNOSTICS PROCEDURE}

Any delay in diagnosis and treatment may lead to irreversible damage to the median nerve, persistent ailments and, as a result, to total inability to work. Early treatment of CTS is likely to bring about total recovery.

The classic diagnostic procedure for CTS is based on the following steps [25, 26]:

1. carefully taken medical history focused on such symptoms as numbness and tingling or pain in the area innervated by the median nerve;

2. physical examination with the use of provocative tests (Tinel's sign and Phalen's manoeuvre) and determination of the vibration perception threshold;

3. median nerve conduction velocity test.

Imaging of the spatial structure of the carpal tunnel can be helpful, in particular in differential diagnosis.

In practice, the conditions connected with the compression of the median nerve are sometimes hard to determine. Most patients who complain of pain and tingling in the entire arm and forearm have difficulties with locating and determining the nature of these conditions. They are not, in particular at the initial stage of the illness, so specific as to guide diagnostic procedure accurately from the very onset. This results in a delay in taking appropriate preventive and therapeutic measures.

On the basis of published clinical experience, a group of researchers reached an agreement on the following issues:

- There is no perfect gold standard for CTS diagnosis. Although findings of electrodiagnostic studies are considered to be the most accurate single tests, false negatives and positives of those findings are well documented.

- A combination of electrodiagnostic studies and characteristic symptoms provides the most accurate diagnosis. Findings of physical examinations add little diagnostic value if electrodiagnostic findings and characteristic symptoms are available.

- In the absence of electrodiagnostic findings, combinations of characteristic symptoms and findings of physical examinations provide the greatest diagnostic information [27].

In their daily practice, occupational medicine physicians taking care of persons performing repetitive manual work, often meet workers complaining of ailments in their upper limbs. That is why, when suspecting CTS, the physician must decide whether the affected person has symptoms of short-lived work overload only or full symptoms of the syndrome.

In any case of suspicion that the pathological changes found are related to professional activities, it is necessary to perform an ergonomic analysis of the workplace of the affected person, i.e., assess the work process taking into account the type of tasks performed by the worker, the posture, repetitiveness rate for working tasks and the length of exposure. Although, in many cases these situations are hard to assess, there are cases in which this analysis should be performed by occupational safety and health (OSH) specialists, as a step before the occupational medicine physician's counselling. In addition, unlike in the case of harmful agents identified in the working environment, occupational medicine does not have any hygienic standards to determine safe working conditions in respect of locomotor system overload. That is why workplace analysis frequently relies on expert knowledge and judiciary practice. In those cases ergonomic standards for the organization of the workplace and its assessment could be applied (e.g., directives, ISO standards, recommendations).

Also indispensable in identifying CTS are preventive entrance medical examinations and preventive periodic medical examinations. 
Methodological guideline concerning the frequency and scope of preventive examination of workers, contained in Annex 1 to the Regulation of the Polish Minister of Health and Social Welfare $^{1}$, provide for such examination in the case of work with video display units (VDU), in a forced body posture, and requiring monotypic limb movements.

In practice, preventive examination of the musculoskeletal system consists of a careful investigation of a history concerning the occurrence of subjective complains (pain, numbness and impairment of motor functions) and analysis of sick-leave periods. At this stage no additional routine examination is carried out.

\section{DIAGNOSTIC METHODS}

\subsection{Clinical Examination}

Clinical examination, which consists of the history, self-administered investigation of subjective symptoms, physical examination and manual provocative test procedure is still a very valuable method used in diagnozing CTS, especially in preventive practice.

\subsubsection{Subjective symptoms}

A diagnosis of a classic form of the syndrome does not present many difficulties. Symptoms may occur bilaterally, but usually they occur in the dominant hand. They include pain, numbness and paraesthesia in the median nerve area, i.e., in the range of the thumb, index finger and middle finger as well as the radial side of the ring finger. The symptoms do not apply to the little finger. Those ailments typically arise or intensify when things are done with a bent wrist and at night. Ailing people wake up, have to move their body and their hand several times for the symptoms to abate (brachialgia parestetica nocturna). In the morning hours fingers seem to be swollen, stiff and clumsy. At this stage there is usually no motor dysfunction or it is insignificant. At the final stage, the motor part of the median nerve is damaged, leading to paresis and muscular atrophy. When giving their medical history, patients report impaired hand function, difficulties with twisting off a jar lid, dropping small objects and other manifestations of motor disorders.

The subjective symptoms of the syndrome are nonspecific. They occur much more frequently than CTS is diagnozed on the basis of objective tests. According to Atroshi, Gummesson, Johnson, et al., if reported subjective symptoms are analysed, CTS is found in more than $14 \%$ of the subjects, while if electrophysiologic examination is used, the syndrome is diagnosed only in $2.7 \%$ of them [28]. Basing on the examination covering a wide population, Tanaka, Wild, Seligman, et al. estimated that only about a third of all persons reporting subjective CTS symptoms (more than 1.8 million) are clinically confirmed [5].

The following criteria have been used in epidemiological studies on the occurrence of CTS, established on the basis of subjective symptoms [14, 29, 30]:

- the occurrence of at least two of three symptoms of damage to the motor part of the median nerve (a tendency to drop small objects, difficulties with twisting off a jar lid and picking up objects and decreased grip strength);

- the occurrence of at least one of three symptoms of damage to the sensory part of the median nerve (numbness in the hand or fingers; pain in the forearms, hand or fingers; or any of these symptoms occurring at night).

To assess the grade of individual symptoms reported by a patient the VAS (visual assessment scale) is useful, whereas to determine localization of these symptoms different diagrams of the upper limbs are in use.

According to studies performed by Franzblau, Salerno, Armstrong, et al., the reliability of

\footnotetext{
${ }^{1}$ Regulation of the Minister of Health and Social Welfare of May 30, 1996, on carrying out medical examinations of workers, the scope of preventive health care and medical certificates issued for the purposes listed in the labour code]. Dz U. 1996;(69):item 332. In Polish.
} 
questionnaires used to assess information related to musculoskeletal symptoms among industrial workers appears to be good to excellent [31]. However symptom surveys collect information that are subjective in nature and have potential to be influenced by psychosocial factors (i.e., organization of work and job satisfaction).

Katz and Stirrat created a method for CTS diagnosis based on a self-administered hand diagram in which patients indicate the anatomic location and quality of their symptoms. Sensitivity and specificity values for the main signs are, respectively,

- 80 and $27 \%$ for pain;

- 97 and $4 \%$ for paraesthesiae;

- 91 and 14\% for nocturnal wakening;

- 51 and $61 \%$ for numbness [32];

- 62 and $52 \%$ for simultaneous paraesthesiae and pain [33].

\subsubsection{Physical examination}

During a medical examination the right and the left hands are compared, with special emphasis on the asymmetry of the muscles in both hands, in the thenar in particular, and the occurrence of other pathologies (e.g., ganglions and swellings) which may compress the nerve. The so-called trigger points and their tenderness can be detected by palpation, which tests inflammation in the structures of the musculoskeletal system.

\subsubsection{Clinical manual provocative tests}

In diagnoses, in particular in epidemiological studies of CTS, there are simple provocative tests typical for the syndrome. These include Phalen's manoeuvre (placing the patient's wrist in a hyperflexed position for 30 to $60 \mathrm{~s}$ causes pain), Flick test (the patient feels pain relief by moving the hand as if shaking down a thermometer), circumduction of the thumb, tests consisting in actively joining fingertips of finger I and V (which causes pain sensation), Tinel's sign (percussion of the tendon in the wrist region causes discomfort or pain at the wrist or radiating distally along the course of the nerve) and McMurthry's test (positive if manual pressure on the palm at the level of the carpal tunnel precipitates painful symptoms or paraesthesiae).

Provocative clinical tests are easy to conduct and may be helpful in screening. One should remember, however, that they contain an element of subjectivity and for that reason they should be interpreted with caution, particularly in the first phase of CTS. Generally speaking, they are thought to be of little use in diagnostic examination. Sensitivity and specificity values for some frequently used tests are presented in Table 1.

TABLE 1. Sensitivity and Specificity of Manual Provocative Tests Used in Diagnozing Carpal Tunnel Syndrome

\begin{tabular}{lccc}
\hline Tests & $\begin{array}{c}\text { Sensitivity } \\
(\%)\end{array}$ & $\begin{array}{c}\text { Specificity } \\
(\%)\end{array}$ & Source \\
\hline Phalen's & 71 & 80 & {$[34]$} \\
manoeuvre & 58 & 54 & {$[33]$} \\
& $43-86$ & $48-67$ & {$[35]$} \\
& 73 & 36 & {$[36]$} \\
Tinel's sign & 42 & 63 & {$[33]$} \\
& 44 & 94 & {$[34]$} \\
& $45-63$ & $40-67$ & {$[35]$} \\
& 62 & 66 & {$[36]$} \\
McMurthry's test & 49 & 54 & {$[33]$} \\
\hline
\end{tabular}

\subsection{Determining Vibration Perception Threshold}

In the practice of an occupational medicine physician, vibration perception threshold tests are generally applied in diagnozing the neurovascular form of the vibration syndrome. They are also useful in suspected peripheral neuropathies, such as diabetic polyneuropathy and CTS [29, 37]. Interpretation of those tests requires taking into account methodological difficulties, including the influence of disturbing factors, such as ambient temperature, daily fluctuation of the vibration perception threshold or the subject's gender and age [38]. In peripheral neuropathies, and thus also in CTS, there is an increased vibration perception threshold. Compared to nerve conduction velocity tests (see section 4.3.), vibration perception threshold tests are noninvasive, well-tolerated and easy to perform; as such, they are useful in diagnozing CTS [39, 40, 29, 41]. Sensitivity and 
specificity vibration perception threshold tests vary depending on the position of the hand during the measurements. The best results are obtained when the wrist is flexed or in an extended position [41, 42].

\subsection{Electrophysiological Examination}

Electrophysiological examination based on the motor and sensory median nerve conduction in the carpal tunnel is a decisive test verifying a CTS diagnosis [30, 43, 44]. According to Nathan, Keniston, Meadows, et al., this test represents a gold standard in CTS diagnostics [45]. Based on an objective measurement, it detects sensory and motor neuropathies in the median nerve, thus confirming the pathomechanism of CTS symptoms. Although the incidence rate of subjective ailments typical of CTS in the professionally active population is high and exceeds the number of CTS cases confirmed by objective studies, there are reports of confirmation by electrophysiological examination of the features of nerve conductivity damage in persons who have not reported subjective symptoms [26, 31].

Electrophysiological examination is highly specific in a clinical setting and reasonably sensitive. Sensitivity and specificity vary for different electrodiagnostic techniques that diagnose CTS. According to a report of the American Association of Electrodiagnostic Medicine, the American Academy of Neurology and the American Academy of Physical Medicine and Rehabilitation the value of sensitivity is from 62 to $85 \%$ and of specificity from 94 to $99 \%$ [46]. According to other sources sensitivity is from 33 to $74 \%$ and specificity from 83 to $100 \%$, depending on the electrodiagnostic techniques used [47].

Electroneurography (ENG) is used for quantitative assessment of parameters characterizing nerve conduction, such as conduction velocity, latency times and amplitude of the signal. These parameters are estimated on the basis of the measurement of the time necessary for a nerve impulse to travel the section between the point of stimulation of the median nerve and the point of measurement.
Compared to healthy individuals, in persons with CTS the conduction velocity in the median nerve is reduced, latency times are increased and the amplitude of the recorded potential is decreased [48].

Results of electrophysiological examinations are also used in classification systems of the CTS sensitivity [49, 50]. All electrophysiological examinations ought to be performed in accordance with guidelines for measurement, temperature, safety precautions and electrode placement.

\subsection{Imaging}

Three radiological methods are used in CTS imaging diagnostics: classic roentgenogram (RTG), magnetic resonance (MR) and ultrasonography (USG). RTG only makes it possible to assess the osseous structures of the wrist, which may be of importance in detecting bone anomalies causing median nerve compression. The assessment of the median nerve structure as such is possible with MR and USG imaging [51]. Compared to MR, USG is cheaper and definitely more accessible; for this reason this is an increasingly frequent form of imaging in cases of suspected CTS [52]. Additionally, USG is so-called real-time imaging, making imaging of wrist structures possible while patients move their fingers. That is why it is also a valuable test used for differentiating tendon and nervous structures and for confirming inflammation of tendon sheaths.

In USG testing, in the case of suspected CTS, thickness and echogenicity of the median nerve, and the existence of the cause of compression are evaluated.

The features found in CTS, in USG, and also in MR include

- decreased thickness of the median nerve in the carpal tunnel, swelling in the proximal part, reduced echogenicity and increased palmar displacement of the flexor retinaculum [53, 54];

- presence of compression causes (e.g., inflammation of the flexor tendon sheaths, radio-carpal joint inflammation and anomalous 
muscle belly of the flexor in the carpal tunnel) [52].

The most reliable sonographic criterion of CTS is the cross-sectional area of the median nerve at the entrance to the carpal tunnel (i.e., at the level of the pisiforme bone). According to different authors, it ranges from 0.07 to $0.20 \mathrm{~cm}^{2}$, depending on the calculating methods used (Table 2). Similar values are used in MR.

\begin{tabular}{|c|c|c|c|}
\hline $\begin{array}{l}\text { Cross-Sectional } \\
\text { Areas of the } \\
\text { Median Nerve } \\
\left(\mathrm{mm}^{2}\right)\end{array}$ & $\begin{array}{c}\text { Sensitivity } \\
(\%)\end{array}$ & $\begin{array}{c}\text { Specificity } \\
(\%)\end{array}$ & Sources \\
\hline$>9$ & 82.8 & 97.1 & [53] \\
\hline 11 & 89.1 & 98.0 & [55] \\
\hline 11 & 73.4 & 57.1 & [56] \\
\hline 9.3 & 92.0 & 98.0 & [52] \\
\hline
\end{tabular}

\section{PREVENTIVE MANAGEMENT}

Despite technological progress, there are still many types of work that involve high repetitiveness of working actions or uncomfortable, forced postures of hands in particular. In the practice of an occupational medicine physician taking care of groups of workers who are exposed to such factors, the fundamental problem, besides exposure to risk factors, is early identification of persons with CTS. Preventive procedures based only on periodic assessment of subjective ailments seem to be unsatisfactory. According to Wainner, Fritz, Irrgang, et al. the development of a Clinical Prediction Rule for diagnozing CTS is mandatory [57]. A Clinical Prediction Rule is defined as "a tool used by clinicians to assist with medical decision making that provides either a probability of disease or outcome or suggest a diagnostic or therapeutic course of action" (p. 490) [58].

Fallentin defines the area of work-related MSDs as a grey zone, in which there is a deficiency of tests to enable actual determination of the incidence rate of this phenomenon and specification of the dose-response relationship, and thus to assess risk at such workplaces [59]. An exhaustive review of epidemiological tests in this regard carried out by the National Institute for Occupational Safety and Health (NIOSH) and National Research Council (NRC) in the USA has revealed lack of studies in this area [18]. The studies carried out thus far have demonstrated that the relationship between the incidence of certain professional factors and the occurrence of MSDs is unambiguous, yet no critical point of exposure to these factors has been identified to date. This issue requires more clinical studies.

\section{SUMMARY}

CTS is one of the best known overload syndromes associated with the type of work. Although factors and pathophysiological mechanisms of CTS are very well understood now, the problem of early diagnosis of this syndrome remains open. Occupational medicine has a battery of clinical and physiological tests which are applied to confirm a diagnosis of CTS. In OSH practice the main goal should be to prevent the onset of a problem or to identify it as soon as possible. To achieve this goal, in addition to the careful and systematic ergonomic analysis of a workplace done by an OSH specialist, periodic examinations of workers exposed to the risk factors of CTS done by occupational medicine physicians seem to be the most appropriate approach.

During those examinations, it is very important for the physicians to be able to conduct simple tests for sensory neuropathy of the median nerve, e.g., tests for the threshold of vibratory sensibility, in addition to interviews and clinical provocative tests. This would make it possiblebecause of the frequent subjective symptoms in the population of workers involved in manual work-to be more precise in identifying people who might have CTS and to refer them quicker to specialist and more expensive diagnostic tests (e.g., ENG and imaging examination). 


\section{REFERENCES}

1. Bugajska J, Łastowiecka E. Analysis of total work inability in Poland in 2000 and 2001 according to age, disease diagnosis and occupation. International Journal of Occupational Safety and Ergonomics (JOSE). 2006;12(3):231-40.

2. Lawrence RC, Helmick CC, Arnett FC, Deyo RA, Felson DT, Giannini EH, et al. Estimates of the prevalence of arthritis and selected musculoskeletal disorders in the United States. Arthritis and Rheum. 1998; 41:778-99.

3. Praemer A, Furner S, Rice DP. Musculoskeletal conditions in the United States. Rosemont, IL, USA: American Academy of Orthopedic Surgeons; 1999.

4. Jędryka-Góral A, Łastowiecka E, Bugajska J. Quality of life in rheumatic diseases and occupational work. Reumatologia. 2004;42(3):458-66. In Polish, with an abstract in English.

5. Tanaka S, Wild DK, Seligman PJ, Haperin WE, Behrens VJ, Putz-Anderson V. Prevalence and work-relatedness of selfreported carpal tunnel syndrome among U.S. workers-analysis of the occupational health supplement data of the 1988 National Health Interview Survey. Am J Ind Med. 1995;27:451-70.

6. Hughes S, Gibbs J, Edelman P, Singer R, Chang RW. Joint impairment and hand function in the elderly. J Am Geriat Soc. 1992;40:871-7.

7. Ilmarinen J. Aging and work-the role of ergonomics for maintaining work ability during aging. In: Bittner A, Champney P, editors. Advances in industrial ergonomics and safety. London, UK: Taylor \& Francis; 1995. p. 15-24.

8. Winn FJ, Morrissey S, Huechtker ED. Cross-sectional differences in nerve conduction in the carpal tunnel syndrome. J Occup Rehabil. 1999;9(1):23-31.

9. Phalen GS. The carpal tunnel syndrome. Seventeen years experience in diagnosis and treatment of six hundred and fifty-four hands. J. Bone Joint Surg Am. 1966;48(2): 211-28.

10. Harrington JM, Carter JT, Birrel L, Gompertz D. Surveillance case definitions for work related upper limb pain syndromes. Occup Environ Med. 1988;55:264-71.

11. Massey EW. Carpal tunnel syndrome in pregnancy. Obstet Gynecol Surv. 1978;33: $145-8$.

12. Murakami T, Tachibana S, Endo Y, Kawai R, Hara M, Tanase S, et al. Familial carpal tunnel syndrome due to amyloidogenic transthyretin His 114 variant. Neurology. 1994;44:315-8.

13. Jensen C. Development of neck and handwrist symptoms in relation to duration of computer use at work. Scand J Work Environ Health. 2003;29(3):197-205.

14. Winn FJ, Krieg EF. The regression model for carpal tunnel syndrome. Proc Soc Exp Biol Med. 1989;192(2):161-5.

15. Burnham R, Chan M, Hazlett C, Laskin J, Steadward RD. Acute median nerve dysfunction from wheelchair propulsion. Arch. Phys. Med. Rehabil. 1994;75: 513-18.

16. Silverstein BA, Fine LJ, Armstrong TJ. Occupational factors and carpal tunnel syndrome. Am J Ind Med. 1987;11:343-58.

17. Putz-Anderson V. Cumulative trauma disorders. New York, NY, USA: Taylor \& Francis; 1988.

18. Bernard BP. Musculoskeletal disorders and workplace factors: a critical review of epidemiologic evidence for work-related musculoskeletal disorders of neck, upper extremity and low back. Cincinnati, OH, USA: U.S. Department of Health and Human Services, National Institute for Occupational Safety and Health, 1997.

19. Bugajska J, Łastowiecka E, Tarnawska S. Simple tasks in the food industry as a risk factor in carpal tunnel syndrome. In: Proceedings of the XVth Triennial Congress of the International Ergonomics Association and the 7th Joint Conference of Ergonomics Society of Korea/Japan Ergonomics Society. Seoul, Korea: Ergonomics Society of Korea; 2003. vol. 4, 567-9.

20. Konarska M, Wolska A, WiderszalBazyl M, Bugajska J, Roman-Liu D. The effect of an ergonomic intervention on musculoskeletal, psychosocial and visual strain of VDT data entry work: the Polish 
part of the international study. International Journal of Occupational Safety and Ergonomics (JOSE). 2005;11(1):65-76.

21. Ali MK, Sathiyasekaran BWC. Computer professionals and carpal tunnel syndrome (CTS). International Journal of Occupational Safety and Ergonomics (JOSE). 2006;12(3)319-25.

22. Freivaldes A. Biomechanics of the upper limbs-mechanics, modeling and musculoskeletal injuries. Boca Raton, FL, USA: CRC Press, 2004.

23. Sunderland $\mathrm{S}$. The nerve lesion in the carpal tunnel syndrome. J Neurol Neurosurg Psychiatry. 1976;39:615-26.

24. Armstrong TJ. Cumulating trauma disorders of the hand and wrist: ergonomic guide. Fairfax, VA, USA: American Industrial Hygiene Association; 1994.

25. Diagnosis of the carpal tunnel syndrome [editorial]. Lancet. 1985;1:854-5.

26. Violante F, Isolani L, Raffi GB. Case definition for upper limb disorders. In: Violante G, Armstrong Th, Kilbom Å, editors. Occupational ergonomics. Work related musculoskeletal disorders of the upper limb and back. London, UK: Taylor \& Francis; 2000. p. 120-8.

27. Rempel D, Evanoff B, Amadio PC, de Crom M, Franklin G, Franzblau A, et al. Consensus criteria for the classification of carpal tunnel syndrome in epidemiologic studies. Am J Public Health. 1998;88(10):1447-51.

28. Atroshi I, Gummesson C, Johnson R, Ornstein E, Ranstam J, Rosen I. Prevalence of carpal tunnel syndrome in a general population. JAMA. 1999;282:153-8.

29. Winn FJ, Morrissey S, Huechtker ED. Cross-sectional comparison of nerve conduction and vibration threshold testing: do screening tools for occupationally induced cumulative trauma disorders result in differing outcomes. Disabil Rehabil. 2000;22(13/14):627-32.

30. Melvin J, Schumann J, Lanese R. Diagnostic specificity of motor and sensory nerve conduction variables in the carpal tunnel syndrome. Arch Phys Med Rehabil. 1973; 54:69-74.
31. Franzblau A, Salerno DF, Armstrong TJ, Werner RA. Test-retest reliability of an upper-extremity discomfort questionnaire in an industrial population. Scand J Work Environ Health. 1997;23(4):299-307.

32. Katz JN, Stirrat CR. A self-administered hand diagram for the diagnosis of carpal tunnel syndrome. J Hand Surg [Am]. 1990;15A(2):360-63.

33. Buch-Jaeger N, Foucher G. Correlation of clinical signs with nerve conduction tests in the diagnosis of carpal tunnel syndrome. J Hand Surg [Br]. 1994;19B(6):720-4.

34. Gellman H, Gelberman RH, Tan AM, Botte MJ. Carpal tunnel syndrome. An evaluation of the provocative diagnostic tests. J Bone Joint Surg Am. 1986;68A(5): 735-7.

35. Massy-Westropp N, Grimmer K, Bain G. A systematic review of the clinical diagnostic tests for carpal tunnel syndrome. J Hand Surg [Am]. 2000;25A(1):120-7.

36. Katz JN, Larson MG, Fossel AH, Liang $\mathrm{MH}$. Validation of a surveillance case definition of carpal tunnel syndrome. Am J Public Health. 1991;81(2):189-93.

37. Winn FJ, Putz-Anderson V. Vibration thresholds as a function of age and diagnosis of carpal tunnel syndrome: a preliminary report. Exp Aging Res. 1990; 16(4):221-4.

38. Lindsell ChJ, Griffin MJ. Normative vibrotactile thresholds measured at five European test centers. Int Arch Occup Environ Health. 2003;76:517-28.

39. Szabo RM, Gelberman RH, Williamson RV, Dellon AL, Yaru NC, Dimick MP. Vibratory sensory testing in acute peripheral nerve compression. J Hand Surg [Am]. 1984;9A:104-9.

40. Gerr F, Letz R, Harris-Abbott D, Hopkins LC. Sensitivity and specificity of vibrometry for detection of carpal tunnel syndrome. J Occup Environ Med. 1995;37:1108-15.

41. Hubbard C, MacDermid JC, Kramer JF, Birmingham TB. Quantitative vibration threshold testing in carpal tunnel syndrome: analysis strategies for optimizing reliability. J Hand Ther. 2004;17(1):24-30. 
42. White KM, Congleton JJ, Pendleton OJ, Huchingson RD, Koppa RJ. Defending the wrist deviation test for carpal tunnel syndrome screening: a comparison of vibration thresholds and distal motor latency. International Journal of Occupational Safety and Ergonomics (JOSE). 1996;2(4):315-335.

43 Kemble F. Electrodiagnosis of the carpal tunnel syndrome. Neurol Neurosurg Psychiatry. 1968;31:23-7.

44. Ghavanini MR, Haghighat M. Carpal tunnel syndrome-reappraisal of five clinical tests. Electromyogr Clin Neurophysiol. 1998;38:437-41.

45. Nathan P, Keniston RC, Meadows KD, Lockwood RS. Predictive value of nerve conduction measurement at the carpal tunnel syndrome. Muscle Nerve. 1993;116:1377-82.

46. Jablecki CK, Andary MT, Floeter MK, Miller R, Quartly CA, Vennix MJ, Wilson JR.Practice parameter-electrodiagnostic studies in carpal tunnel syndrome. Report of the American Association of Electrodiagnostic Medicine, American Academy of Neurology, and the American Academy of Physical Medicine and Rehabilitation. Neurology. 2002;58(11): 1589-92.

47. Lew H, Date ES, Pan SS, Wu P, Ware PF, Kingery WS. Sensitivity, specificity, and variability of nerve conduction velocity measurements in carpal tunnel syndrome. Arch Phys Med Rehabil. 2005;86:12-16.

48. Kimura J, Ayyar DR. The carpal tunnel syndrome: electrophysiological aspects of 639 symptomatic extremities. Electroencephalogr Clin Neurophysiol. 1985;25: 151-64.

49. Nora DB, Becker J, Ehlers JA, Gomes I. Clinical feature of 1039 patients with neurophysiological diagnosis of carpal tunnel syndrome. Clin Neurol Neurosurg. 2004;107:64-9.
50. Padua L, LoMonaco M, Aulisa L. Surgical prognosis in carpal tunnel syndrome: usefulness of a preoperative neurophysiological assessment. Acta Neurol Scand. 1996;94:343-6.

51 Walecki J, Ziemiański A. Rezonans magnetyczny i tomografia komputerowa. Warszawa, Poland: Springer, PWN; 1997.

52. Ciechomska A, Tomczykiewicz K, Bachta A, Tłustochowicz W. Ultrasonograficzna ocena nerwu pośrodkowego w zespole cieśni nadgarstka. Ultrasonografie. 2004;19:36-41.

53. Duncan I, Sullivan P, Lomas F. Sonography in the diagnosis of carpal tunnel syndrome. AJR Am J Roentgenol. 1999;173:681-4.

54. Buchberger W, Judmaier W, Birbamer G, Lener M, Schmidauer C. Carpal tunnel syndrome-diagnosis with high resolution sonography. AJR Am J Roentgenol. 1992;159:793-8.

55. Kele H, Verhaggen R, Bittermann H-J, Reimers CD. The potential value of ultrasonography in the evaluation of carpal tunnel syndrome. Neurology. 2003;61: 389-91.

56. Sarria L, Cabada T, Cozcolluela R, Martinez-Berganza T, Garcia S. Carpal tunnel syndrome: usefulness of sonography. Eur Radiol. 2000;10(12):1920-5.

57. Wainner R, Fritz JM, Irrgang J, Delitto A, Allison S, Boninger ML. Development of a clinical prediction rule for the diagnosis of carpal tunnel syndrome. Arch Phys Med Rehabil. 2005;86(4):609-18.

58. Laupacis A, Sekar N, Stiell IG. Clinical prediction rules. A review and suggested modifications of methodological standards. JAMA. 1997;277:488-94.

59. Fallentin N. Regulatory actions to prevent work-related musculoskeletal disordersthe use of research based exposure limits. Scand J Work Environ Health. 2003;29(4): 247-50. 